\title{
New Tendencies in Studies within Vocational Education in Russia
}

\author{
Anna V. Berestova \\ I.M. Sechenov First Moscow State Medical University (Sechenov University), Russia, \\ anna.berestova.95@bk.ru
}

\author{
Anastasia V. Lazareva \\ Moscow State Institute of International Relations (MGIMO University), Russia, \\ asyalazareva@gmail.com
}

Vyacheslav V. Leontyev

Kazan Federal University, Russia,vleontev@yandex.ru

The vocational education, as the entire system, is undergone constant changes that shape new tendencies. This undoubtedly indicates that it is necessary to know about them and to apply them in a timely manner in the educational process. The purpose of this study was to identify attitudes towards new tendencies and possible issues associated with them. For research purposes the surveys were conducted among university lecturers and students. Fifty five teachers from three Russian universities were surveyed. They teach various specialties, from the humanities to the technical ones. Also, 700 students aged from 18 to 21 have participated in the survey. The survey was conducted among representatives of various specialties. The study has shown that students and teachers are aware of the variability of the educational system and noticed new tendencies in it. They also said that these tendencies are used in their universities. In order to assess the possibilities of expanding the new tendencies in the vocational education, several solutions were proposed: study of curricula and conducting surveys among university employees, explaining their importance, changes in curriculum and organizing optional training meetings with students.

Keywords: new tendencies, vocational education, educational tendencies, Russia, study

\section{INTRODUCTION}

Globally, the demand for highly skilled employees is fast growing in the labor market as the knowledge has become the most important factor in innovation, economic diversification and development (OECD, 2014). Economists and policy makers have identified the higher education as a key mechanism for increasing national productivity and reducing social inequality by extending the economic participation of disadvantaged

Citation: Berestova, A. V., Lazareva, A. V., \& Leontyev, V. V. (2020). New Tendencies in Studies within Vocational Education in Russia. International Journal of Instruction, 13(1), 886-900. https://doi.org/10.29333/iji.2020.13157a 
groups (Piketty, 2014). There is assumption that the increase in educational qualifications will lead to the increase in social mobility (Bathmaker et al., 2013). While undergraduate degrees in universities are still the most common degree, there is currently a serious worldwide movement to meet this need for greater access to higher education. Vocational schools, such as additional education colleges (including technical and additional educational institutes) that specialize in vocational education and training, as well as qualifications for professions, offer bachelor's degrees (OECD, 2015). Therefore, the orientation of educational institutions and students towards expanding participation policy and practices has been changed for higher professional education in non-university higher educational institutions (Trow, 2006).

Changing and improving educational practices and measuring the impact of educational policy are not as simple as it seems. These changes require modifications and serious involvement in many areas that are interconnected. In addition, not everyone can immediately accept them. Most of these changes occur at the state level, which requires the adoption of relevant laws and their gradual implementation. Experts from different areas of educational evaluation research warn that such development is difficult to implement. Moreover, what seems like a "quick solution" in education rarely, if ever, "corrects" something and never happens "quickly". This suggests that all tendencies in education have been gradually developed, undergoing various changes in the process (Gregson \& Nixon, 2009).

General education and vocational education are inseparably associated. The choice of high school has a significant impact on the future career options of a young person. This educational system is a starting point for further education and training of young people. This testifies that the selection of the secondary school will tremendously influence a future professional development (James \& Biesta, 2007). Not all companies provide training for the student, and, notwithstanding its fixed schedule, the standards of vocational training can vary considerably. Training students for the same profession in different companies can provide very different working options. Larger companies that ensure significant primary education opportunities may offer their own educational seminars or training centers. So, smaller companies, when they themselves conduct primary education, often encourage and render opportunities for an independent work and improved communication skills (Appleby \& Hillier, 2012). Thus, among young people there is a big competition for organizations that are universally considered as interesting for those candidates, who are called "white-collar" ones, such as banking and finance, or large transnational companies. This determines that employers, offering "attractive" internships, can choose among highly qualified candidates, while employers in less privileged industries face difficulties in finding candidates of the required level.

The competency-based education has become a dominant tendency in vocational education in several European countries (Clarke \& Winch, 2007). However, this education is a term encompassing various ideas and practices, there is agreement on certain features. Competency-based vocational education implies the integration of knowledge, skills and attitudes as the targets of the training programs. In addition, the competence education uses realistic tasks in real conditions. Authentic and functional 
learning is supported by learning basic knowledge and learning specific skills. Finally, there is an agreement on the assessment of learning outcomes: assessment during courses supports a professional development, and the final assessment focuses on the quality of professional activity in authentic contexts (De Bruijn, 2004). In the course of educational system extension the vocational education has also acquired some tendencies and changes, namely, some of them are the following: the competency-based vocational education has a powerful learning environment. This implies a focus on the zone of proximal development, wide opportunities for cooperative and interactive learning, learning in an authentic context and in various situations, complex learning tasks, reflective and emotional one (Renshaw, 2004).

Combining proven teaching methods with experimental ones is important for the implementation of the concept of learning, in which courses are not designed in advance, but are developed specifically for them. Proven methods are still useful and effective, but differ functionally. Such methods include group or classroom instruction and instructional learning with a teacher regarded as an expert in a discipline or subject. Teachers must find a proper balance to be able to develop a concept for vocational training. It is extremely important to develop a new teaching practice, in which various methods are flexibly used depending on the situation, goals and needs of students (Biemans et al., 2009).

Teaching identity (Meijers, 2002) is another tendency in the vocational education field and relates to the formation of a professional identity. This is not only related to professional knowledge and skills, but also includes attitudes and typical habits in the relevant profession, that is, professional habitat (Colley et al., 2003). Thus, the professional identity ensures a common basis for the development of knowledge, skills and attitudes during a professional course aimed at integrating thinking, actions and knowledge (De Bruijn \& Leeman, 2011).

Finally, self-control is an important objective and aspect of the vocational education. External control and discipline may be necessary on a temporary basis, but this should be considered in terms of transferring control function to the students themselves. Successful transfer of control during the course is characterized by careful and adaptive balancing, upon which constructive friction is created, and students feel encouragement and challenge. In this tendency, three teaching methods are important (Van de Pol et al., 2011):

Monitoring: a teacher is a manager, the importance of this role is gradually lowering down, but he/she is always working upon the principle of "an external eye" towards metacognitive and emotional processes.

Management: the teacher plans and schedules possible training actions, offering transparent options.

Patterns' formation: the teacher uses patterns at each stage of the education, gradually using them less and less as soon as students have acquired respective skills, transfer to another stage and the learning process is repeated. Training materials and technological devices are auxiliary tools in this process (De Bruijn, 2012). 
Thus, this testifies that tendencies in a modern, professional education play a great role as they influence its development as well as students' learning. This issue can be considered as multi-faceted. In view of it, there are following objectives of the study:

. $\quad$ select key new tendencies in a vocational education in Russia;

- conduct the survey among students and teachers in order to clarify how these tendencies are applied in the Russian higher education institutions;

based on obtained results to find out possible solutions.

\section{LITERATURE REVIEW}

According to De Bruijn (2012) the orientation of vocational education towards competence-based education has led to fundamental changes in the work of vocational education teachers. This article pictures teaching in innovative, competence-based vocational education. By examining not only the actual behaviour of teachers but also their related personal ideas and professional attitudes, the ways teachers implement new educational concepts and their experienced uncertainties, dilemmas and practical tensions can be examined. These insights lead to a better understanding and specification of the concept of competence-based vocational education at the micro level of educational processes, that is, the interaction between teachers and students. Implications are described in terms of new repertoires of teaching behaviour and teaching methods - all in the context of vocational education.

Billett (2013) also states that standing of vocational education is salient for how it is perceived by those who sponsor, participate in and work within it and how its provisions are supported and administered. Yet, this standing continues to be intractably low, compared with other education sectors, more so in some countries than others. The consequences for this low standing can be profound. Serially, moreover, it has been the voices and sentiments of powerful others (e.g. aristocrats, theocrats, bureaucrats and academicians) that have long been privileged in discourses about the standing of occupations and their preparation. In perhaps most instances, this privileging has and continues to come at a cost to the standing, processes of and goals for this important educational sector. Indeed, the legacies of earlier sentiments about and conceptions of different kinds of occupations and their preparation are now deeply embedded in societal discourses and variously sustain and constrain the standing of vocational education. Sennett (2008) adds that concepts such the Berufs concept in the German speaking world does much to sustain and elevate vocational education. Elsewhere, this lowly standing generates constraints that comprise efforts to control and micro-manage those who teach and learn. Adopting a historical approach, this paper offers a brief and partial account of how, across time, sentiments of powerful others have shaped the standing of vocational education and its proposes and practices, often for purposes of power and control. Instead, it is proposed that for vocational education to realize its purposes necessarily requires it to be informed by and directed more by the interests of those learning about - teaching and practice - these occupations. In addition, the need for societally based (i.e. governmental) imperatives to ameliorate the long-standing consequences of these sentiments for vocational education is proposed. 
Only recently have some authors begun to focus on the role of employees with a VET profile in innovation activities, linking elements from different theoretical traditions such as 'varieties of capitalism', 'high-performance work systems' and innovation studies (Toner, 2011). In this regard, some writers have noted that technical workers with intermediate qualifications are involved in the design, installation, operation and maintenance of products and processes and that they, therefore, contribute - or can contribute - to innovation in these firms (Tether, Mina, Consoli, \& Gagliardi, 2005; Toner, Marceau, Hall, \& Considine, 2004).

In Europe, the only studies of this kind have been conducted in the Basque Country and Navarre (Spain), industrial regions in which regional governments have made a strong commitment to strengthening vocational studies. Following the classification of Rosenfeld on the missions of VET institutes (formal education, continuous training and company services), Albizu, Olazaran, Lavía, and Otero (2011) analysed the relations between those institutes and industrial SMEs in the Basque Country. They suggested that vocational training centres are an agent of significance within the regional innovation system, contributing through their main lines of action to improving the competitiveness of companies and to stimulating their innovation processes. Subsequently, a study by Lavía, Olazaran, Albizu, and Otero (2012) showed that companies that perform more continuous training with VET centres express greater agreement on the effects of training on motivation, productivity and worker contribution, although the levels of agreement on the direct effects on innovation of the continuous training these centres offer were somewhat lower. Recently, Lavía, Otero, Albizu, and Olazaran (2016), using a new sample from the Basque Country, have studied in more detail the presence of VET employees in industrial SMEs and their participation in innovation activities.

\section{METHOD}

\section{Research Design}

Based on the specified objectives, for the collection of information, it was decided to conduct an empirical study, which comprised a survey of students and teachers. The study used the methodology of quantitative research to collect and analyze interpretations and values of the survey.

\section{Participants}

Surveys were conducted among teachers to assess attitudes towards new tendencies in vocational education. Fifty five teachers from three Russian universities were surveyed. They have taught various specialties, from the humanities to the technical. Out of them there are 31 women and 19 men. The average age of respondents was 42.3 years (see Table 1).

Participation in the survey was offered to several large Russian universities. Before participating in the survey, teachers had to sign a consent. Representatives of the following three institutions have agreed. 
Table 1

Respondents-Teachers of Higher Education Institutions

\begin{tabular}{ll}
\hline Name of educational institution & Quantity of surveyed \\
\hline Plekhanov Russian University of Economics & 20 \\
\hline Higher School of Economics & 13 \\
\hline Moscow state university & 22 \\
\hline
\end{tabular}

Also, 700 students aged from 18 to 21 participated in the survey. Among them, $53 \%$ of women and $47 \%$ of men. All students are full-time students (see Table 2).

Purposive sampling was considered the most appropriate sampling method. In order to extend fully the research framework upon existing limitations of the questionnaire, a survey was conducted among students from the first to the fourth year of study.

Table 2

Respondents-Students

\begin{tabular}{ll}
\hline Name of educational institution & Quantity of surveyed \\
\hline Lomonosov Moscow State University & 168 \\
\hline Bauman Moscow State Technical University & 146 \\
\hline $\begin{array}{l}\text { Moscow State Institute of International Affairs of the Ministry of Foreign } \\
\text { Affairs of the Russian Federation }\end{array}$ & 89 \\
\hline \begin{tabular}{l} 
Higher School of Economics \\
\hline Moscow Power Engineering Institute (National Research University)
\end{tabular} & 150 \\
\hline
\end{tabular}

\section{The Participant's Selection Criterion}

First and fourth year students were chosen to expand the study coverage. In addition, for the same purpose, the survey was conducted among representatives of various specialties, including: "Medicine", "Russian Language and Literature", "Mechanical Engineering Technologies", "Computer Science and Management Systems", "Linguistic and Regional Studies and Intercultural Communication", "Journalism", "Philology", "Mechatronics and Robotics", "Ecology", "Commercial Affairs"and "Power Engineering". This will allow a more complete assessment of the situation related to tendencies in modern vocational education.

The survey as among teachers and as among students is stipulated by the fact that their attitude to the topic of tendencies in vocational education may be different. This will allow to evaluate the view on the situation from the side of both teachers and students.

\section{Research Limitations}

The study involved only students and teachers of the Russian higher educational institutions. That is why, there is no information regarding the attitude of students and 
teachers of foreign educational institutions towards this topic. Also, the survey was conducted only among students of the largest Russian higher educational institutions, where innovations in the educational process are more likely to be used. This information does not allow to have more clear view on the situation in more provincial educational institutions. In addition, the data obtained in the quantitative analysis can be quite general.

\section{Research Instruments}

With the purpose of study performance there were two surveys. The first survey was conducted among students. It was a questionnaire of eight questions in which students were asked to choose a positive or negative answer by expressing their opinion (see Table 4 in Appendix 1).

The second part of the study referred to teachers. There was a table in which several of the most common tendencies in vocational education with a description were presented. Teachers were proposed to choose those that, in their opinion, are the most common. They could choose more than one option (see Table 3 ).

Table 3

Survey for Teachers

\begin{tabular}{ll}
\hline Tendency & Description \\
\hline Teach to be result-oriented & $\begin{array}{l}\text { In the framework of higher education students are taught to } \\
\text { achieve a real result. }\end{array}$ \\
\hline Mentoring & $\begin{array}{l}\text { The teacher acts also as an assistant, that is to manage the } \\
\text { activity of the student in a definite direction }\end{array}$ \\
\hline $\begin{array}{l}\text { Impossibility to transfer } \\
\text { knowledge without training }\end{array}$ & $\begin{array}{l}\text { The teacher, based on the knowledge of which students are } \\
\text { aware, develops their professional skills }\end{array}$ \\
\hline $\begin{array}{l}\text { Support programs as for quality of } \\
\text { education }\end{array}$ & $\begin{array}{l}\text { Submission of necessary information to teachers and students } \\
\text { (for example, special programs, training course, etc.) }\end{array}$ \\
\hline Remote education & \begin{tabular}{l} 
Online learning \\
\hline Social media
\end{tabular} \\
\hline $\begin{array}{l}\text { Obtaining the information from the internet by students, using } \\
\text { different training resources }\end{array}$ \\
\hline Development of stress resistance & \begin{tabular}{l} 
Capability of the students to tackle with non-standard situations \\
\hline
\end{tabular} \\
\hline
\end{tabular}

Eight items were presented to teachers for selection, which can be referred to both professional and higher education as a whole. Among them there are tendencies related to various aspects: personal, informational, as well as general educational. The data obtained from this survey will help to assess what tendencies in vocational education are considered as most important by teachers. 


\section{Data Analysis}

After collecting the necessary information, the analysis of the research data was performed in the STATISTICA system. This software, developed on the basis of Microsoft Windows, allows visualizing the data under the statistical analysis. The error makes up 4\%, about 28 questionnaires have been incorrectly filled in (some respondents did not answer all the questions or chose more than one answer).

When analyzing each answer (answer option), the number of respondents who selected it was calculated. Further, when calculating the results, the data were converted into a percentage ratio calculated from the total number of respondents for each item.

\section{FINDINGS}

As for the first question, the result was predictably high, 94\% of respondents agreed that modern education is undergoing many changes. This testifies that students have perceived these changes, as many of them relate directly to the students themselves. The data on the second question also turned out to be high, as $88 \%$ of respondents believe that there are new tendencies in vocational education. This also indicates that they understand changes, regardless of the type of education. Surprisingly, the answers under the next question have been divided almost equally. 53\% of the respondents considered the promotion of self-education as a modern tendency, while $47 \%$ disagreed with them. Such a result is probably caused by the fact that self-education is not a new phenomenon that a student is aware.

Regarding the next question, the students' opinion turned out to be almost unanimous. $95 \%$ of respondents agreed that the development of computer technology influence new educational tendencies. This testifies that the respondents understand the technological approach in education.

The results upon the next question were also quite high. $74 \%$ of respondents considered the remote education as a new tendency. $26 \%$ of those who did not agree due to two reasons: remote education has become habitual for them and does not seem to be something new, and they do not realize that this phenomenon can be considered a modern tendency. In terms of the following question, the data were unexpectedly low. Only $38 \%$ of the respondents agreed that the development of stress resistance can be considered as a new tendency. Such a result can be justified by the fact that the development of stress resistance has carried out unnoticeably, not as a separate course, because of which students may simply be unaware of it. Rather large percentage of respondents $(71 \%)$ agreed that the new tendencies have a positive effect on the educational system. Answering this question, students were asked to express their opinions, $29 \%$ of those who did not agree could choose a negative answer because of their personal preferences. The majority of respondents $(91 \%)$ noted that new tendencies are present to some extent in their higher educational institutions. This result was expected, as almost in any modern educational institution there are at least some innovations. 
After analyzing the student survey, the survey for teachers was analyzed. As a result, the data are presented in the diagram.
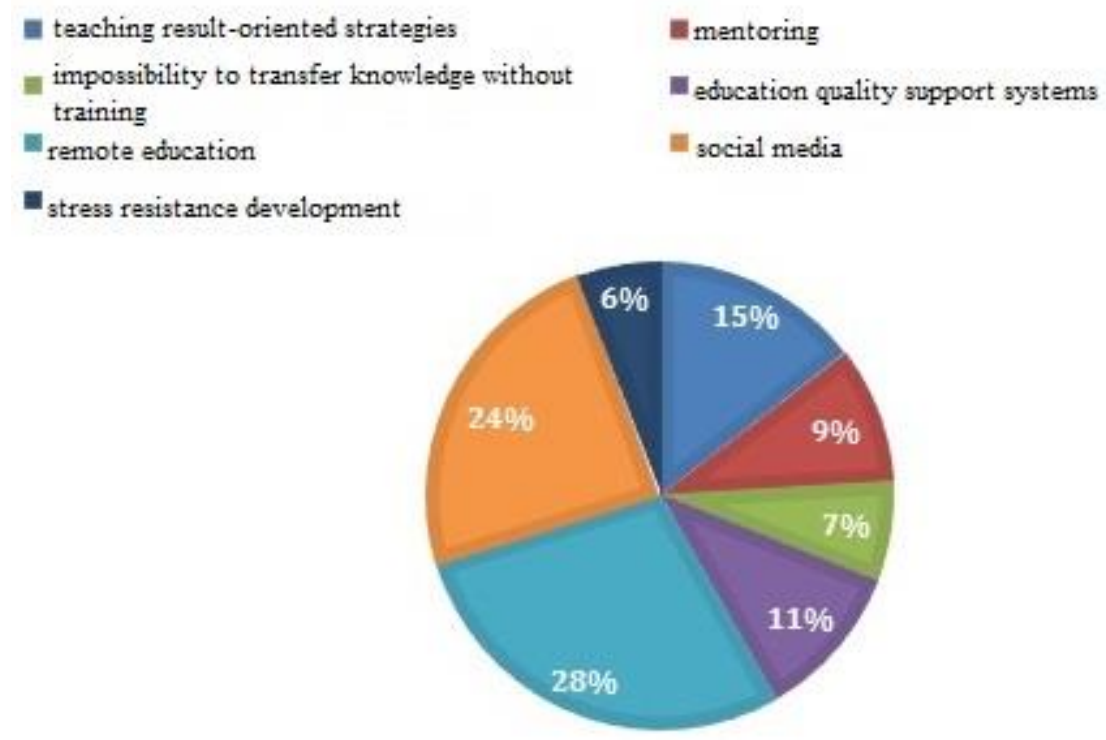

Figure 1

Teacher Survey

Thus, the most popular answers were "remote education" and "social media". This may indicate that the remote education is currently one of the most well-known and wellestablished tendencies. A large percentage of the item "social media" indicates that teachers are aware that contemporary students receive a lot of information from outside, using the Internet. Also, a good result was shown by the item "teach to be resultoriented". This suggests that university studies are not primarily theoretical in nature, but are aimed at practical knowledge. The lowest results showed items "impossibility to transfer knowledge without training" and "stress resistance development". The reason is, as in the case of students, may be that these phenomena do not have separate courses, but are trained in the process of others, which may lead to an incomplete awareness of their application.

\section{Consideration of the curriculum of higher educational institutions and surveys' execution}

In order to understand whether new tendencies are applied in a particular educational institution, it is necessary to comprehend their structure. To fulfill it, the curriculum can be analyzed, as well as training courses provided, which will help to determine the existence or absence of any tendencies. In addition, a survey among teachers and management of higher educational institutions can be organized, in which they could express their opinion about whether current tendencies are used in their organization. 


\section{Clarification of the importance of modern tendencies}

In order to apply up-to-date tendencies in training process, both teachers and management must be aware of their benefits. For this purpose, special lectures can be held at which the advantages of new tendencies' usage would be shown. In addition, at these courses more details about the various tendencies can be provided, so that participants can conclude which of the latter will be adaptable for higher educational institutions, specialty, etc.

\section{Change of curriculum}

After conducting research, surveys and / or courses, it is necessary to revise the curricula and, if necessary, adjust them in order to have a space for the application of new tendencies.

\section{Non-official environment}

Non-formal learning is an informal, unplanned, sometimes spontaneous means of acquiring knowledge and skills. Quite often, people get the necessary knowledge from random materials in the Internet, conversations with colleagues during a break, etc. And although such training usually takes place in the workplace, universities could adopt some useful "operational" practices. For example, informal meetings between teachers and students with discussions and exchanges of views over a cup of tea can be organized. Such a practice can not only help to improve students' knowledge, but also to increase interest in learning, as well as to contribute to better relationships with teachers.

As can be seen from the results of the study, both students and teachers consider new trends necessary in higher education. Such a result can be considered positive, since awareness of the importance of a phenomenon can contribute to its faster implementation. It can be assumed that in this situation, the proposed options for the dissemination of new trends in education will be more quickly accepted and used in practice. This should entail an improvement in the quality of higher education.

\section{DISCUSSION}

The study of new tendencies in vocational education attracts quite a lot of attention; therefore, research in this area is being conducted in different countries. The one of such studies was conducted in the Netherlands in 2012 (De Bruijn, 2012). This article focuses on teaching innovative vocational education in the Netherlands. In several case studies, teaching methods of 10 teachers from five vocational schools were carefully examined. Analyzing not only the real behavior of teachers, but also related personal ideas and professional views, it was considered how teachers implement new educational concepts, as well as their feelings associated with uncertainty, dilemmas and practical tension. This study has led to a better understanding and, more detailed and concise concept of vocational education based on competences at the micro level of educational processes, that is, the interaction between teachers and students.

To answer the research questions, the design of several case studies was chosen. Each teacher was identified as a separate entity and was studied in detail (Yin, 2003). 
The objective of this study was to examine the practice of teachers who have succeeded in the performance of vocational education based on competencies, as teachers are not very easily changing their teaching approach. Therefore, schools were chosen that were known for the introduction of new tendencies (as stated in the reports of the Education Inspectorate and in interviews with key persons). Because vocational schools offer programs in different professional fields - each of which has its own history of innovation. The educational institutions were chosen rather than schools (Windschitl, 2002).

Following the confirmation of a school administration in terms of its cooperation, a stepby-step method was used to select teachers. Firstly, for each faculty there was chosen a specific educational program based on the history of innovation. Secondly, consultations were held with the coordinator of this program to determine which team members have had already many years of teaching experience in vocational education grounded on competencies. Thirdly, in order to confirm the proposals of the coordinator, the selected teachers were asked to fill a short questionnaire in regarding their experience in implementing vocational education based on competencies. Fourthly, teachers were asked about their willingness to participate in research projects, as this would be an intensive activity for them (Siegel, 2000).

In the end, ten teachers agreed to participate in the study; seven men and three women. All of them had at least three years of experience in vocational education based on competencies and were delighted with it. Half of them were the initiators of innovations in their school departments and / or the developers of educational materials. The teachers were trained in programs for various skill levels and in various specialties, namely technical specialties, administration, information technology and health care. In addition, they also taught various subjects and skills, from English and mathematics to mentoring and practical exercises (De Bruijn, 2012).

The data were interpreted according to a step-by-step procedure (Miles \& Huberman, 1994). First, for each teacher, the conceptual maps and the observed behavior of the teacher were interpreted using a process by which the leadership features served as a coding scheme. Secondly, using the same coding scheme, the observed pedagogical activity was systematically compared with (a) personal ideas and professional attitudes of the teachers themselves and (b) the formal theory defined in our conceptual structure. Each case (teacher) was studied and deciphered by one researcher, and the second researcher questioned the process of interpretation and analysis through written comments. In the final session, two researchers discussed the results until a consensus was reached. This cooperation can be considered an intensive form of interviewing colleagues. As a result of data analysis, a report was compiled for each teacher (Gregson \& Nixon, 2009).

The survey results demonstrate that teachers have met some difficulties with their new roles, although they themselves have chosen these new professional models with confidence. Notwithstanding that they were identified as founders of tendencies, they have still tested and searched for adequate behaviors. So, their personal ideas and professional views, as well as their pedagogical behavior have expressed their attempts. 
Thus, it confirms the theories and assumptions stipulated above that the implementation of new concepts is not just their application in practice (Windschitl, 2002).

Regarding the first research question about the personal ideas and professional attitudes of these teachers, it can be concluded that teachers suggest that stimulating selfeducation in an adaptive, gradual manner is a starting point for their pedagogical behavior (Kelchtermans, 2009). Combining proven methods with experimental ones, that is the second feature, is deemed a concept that often refers to the transfer of selfeducation from teacher to student. Teachers find two other features that create a powerful learning environment and accept identity formation as the basis for teaching, preferably. But, the latter are less specific regarding the meaning of these two features and how to carry out them into practice. They used different teaching methods to stimulate self-control, to combine theory with practice as well as the application of theoretical models and basic knowledge (Enthoven \& De Bruijn, 2010).

The adaptive pedagogical behavior, as it turned out, was natural for teachers. However, only a few teachers used teaching methods to go beyond a specific learning environment. The latter have used vocation as the basis for synthesizing primary theory, skills, habits and attitudes. They focused on shaping the professional identity of their students and often themselves behaved as role models. Observations on the behavior of teachers have already shown clear discrepancies between personal ideas and professional attitudes, on the one hand, and the actual behavior of teachers, on the other hand. (Billett, 2001). Another study related to vocational education was conducted in China in 2009. This study was conducted at the International Vocational College of Design and Business, located in central Shanghai in 2005 and 2006. The purpose of the study was to properly align the learning outcomes with the requirements of employers and to find out the opinion of employers on future tendencies. The sample included key college stakeholders, namely: employers; students, graduates and academic staff. A survey design was used that requested both qualitative and quantitative information from the sample (Velde, 2009).

For this study, there was used such a survey form that implies usage of questionnaires for data collection from employers. Thus, the research method was multifaceted to reveal the views of various stakeholders. The sample included 27 employers from design and commercial companies operating as small and medium enterprises that were associated with the college. The Employer Questionnaire included both qualitative (open) and quantitative (closed) questions to enable them to appreciate the importance of the traits and qualities of the graduate and enable employers to express their views asking more open questions (Venter, 2003).

The questionnaires were compared for data analysis. They were numbered in chronological order because they were anonymous to ensure confidentiality. Quantitative data were presented in the form of tables and figures, and qualitative data were summarized and compiled under the relevant questions. The results of this study have demonstrated that employers consider the "commitment to learn and constantly develop" and "the ability to think creatively and solve issues" as extremely important. These results suggest that employers expect graduates to be ready to acquire new skills 
in order to keep up with a rapidly changing environment and be responsible for their own learning (Hodges and Burchell, 2003). The results of this study also indicate that employers go beyond the scope of "specialized knowledge and skills in a particular field". While employers in this study have paid more attention to "proper relationships and abilities," results, emphasized the importance of "continuous learning" and "problem solving and creativity", testify that such a tendency is affected by the developed market economy in China (Venter, 2003).

\section{CONCLUSION}

During the study the students are turned out to be aware of the variability of the educational system and identify new tendencies in it. They also commented that these tendencies are present in their higher educational institutions. However, the students haven't been always evaluated properly this or that innovation. As for teachers, they also understand the importance of new tendencies, although they also do not always highlight some of them.

In order to expand the application of new tendencies in vocational education, certain solutions have been proposed. In order to understand whether new tendencies are applied in a particular educational institution, it is necessary to understand their structure. Following it the analysis of the curricula can be fulfilled, as well as the courses provided, which will help to determine the usage or absence of any tendencies. In addition, a survey among teachers and management of higher educational institutions can be organized. To use contemporary tendencies in educational process, both teachers and management must be aware of their benefits. For it, special lectures can be held at which the advantages of the application of new tendencies would be shown.

After conducting research, surveys and / or courses, it is necessary to revise the curricula and, if necessary, adjust them to enable the application of new tendencies. Informal meetings of teachers and students with discussions and exchanges of views over a cup of tea can be organized. Such a practice can not only help to improve students' knowledge, but also increase interest in learning, as well as contribute to better relationships with teachers.

Next study can also be extended in scope and volume. Among the students are masters or college students. Moreover, a similar study can also be carried out among citizens of other countries. The best practice and results of the research can be taken as a basis for conducting other surveys or comparing with statistical data of different years dencies would be shown.

\section{REFERENCES}

Albizu, E., Olazaran, M., Lavía, C., \& Otero, B. (2011). Relationships between vocational training centres and industrial SMEs in the basque country: A regional innovation system approach. Intangible Capital, 7(2), 329-355.

Appleby, Y. \& Hillier, Y. (2012). Exploring practice-research networks for critical professional learning. Studies in Continuing Education, 34(1), 31-43. 
Bathmaker, A.-M., Ingram, N. \& Waller, R. (2013). Higher education, social class and the mobilisation of capitals. British Journal Sociology of Education, 34(5-6): 723-743.

Biemans, H., Wesselink, R., Gulikers, J., Schaafsma, S., Verstegen, J. \& Mulder, M. (2009). Towards competence-based VET: Dealing with the pitfalls. Journal of Vocational Education and Training, 61, 267-286.

Billett, S. (2001). Knowing in practice: Re-conceptualising vocational expertise. Learning and Instruction, 11, 431-452.

Billett, S. (2013). The standing of vocational education: sources of its societal esteem and implications for its enactment. Journal of Vocational Education \& Training, 66(1), $1-21$.

Clarke, L., \& Winch, C. (2007). Vocational education. International approaches, developments and systems. London: Routledge.

Colley, H., James, D., Tedder, M., \& Diment, K. (2003). Learning as becoming in vocational education and training: Class, gender and the role of vocational habitus. Journal of Vocational Education and Training, 55, 471-498.

De Bruijn, E. \& Leeman, Y. (2011). Authentic and self-directed learning in vocational education: Challenges to vocational educators. Teaching and Teacher Education, 27, 694-702.

De Bruijn, E. (2004). Changing pedagogic and didactic approaches in vocational education in the Netherlands. From institutional interests to ambitions of students. European Journal of Vocational Training, 31(1), 27-37.

De Bruijn, E. (2012). Teaching in innovative vocational education in the Netherlands. Teachers and Teaching, 18(6), 637-653.

Enthoven, M., \& De Bruijn, E. (2010). Beyond locality: The creation of public practice based knowledge through practitioner research in professional learning communities and communities of practice. A review of three books on practitioner research and professional communities (Essay Review). Educational Action Research Journal, 18(2), 273-289.

Gregson, M. \& Nixon, L. (2009). Assessing effectiveness: Ways of seeing impact. International Journal of Interdisciplinary Social Sciences, 21(3).

Hodges, D. \& Burchell, N. (2003). Business graduate competencies: Employers' views on importance and performance. Asia-Pacific Journal of Cooperative Education, 4(2), $16-22$.

James, D., \& Biesta, G. (2007). Improving learning cultures in further education. London: Routledge.

Kelchtermans, G. (2009). Who I am in how I teach is the message: Self-understanding, vulnerability and reflection? Teachers and Teaching: Theory and Practice, 15, 257272. 
Lavía, C., Olazaran, M., Albizu, E., \& Otero, B. (2012). Formación continua en centros de FP y actividades de innovación en las pymes industriales. Arbor, 188(753), 153-170.

Lavía, C., Otero, B., Albizu, E., \& Olazaran, M. (2016). Perfiles empresariales y participación de los trabajadores con cualificaciones intermedias en actividades de innovación: el caso del País Vasco. Revista Española de Sociología, 25(3), 61-80.

Meijers, F. (2002). Career learning in a changing world: The role of emotions. International Journal for the Advancement of Counselling, 24, 149-167.

Miles, M. B., \& Huberman, A.M. (1994). Qualitative data analysis: An expanded sourcebook. Thousand Oaks, CA: Sage.

OECD. (2014). Skills beyond School: Synthesis Report. Paris: OECD

OECD. (2015). Education at a Glance 2015: OECD Indicators. Paris: OECD.

Piketty, T. (2014). Capital in the Twenty-first Century. Harvard: Harvard University.

Renshaw, P. D. (2004). Dialogic learning teaching and instruction. In J. van der Linden, \& P. Renshaw (Eds.), Dialogic learning (pp.1-15). Dordrecht: Springer.

Sennett, R. 2008. The Craftsman. New Haven, CT: Yale University Press.

Siegel, G. (2000). Skills needed for entry-level management accounting positions. Strategic Finance, 81(10), 79-80.

Tether, B., Mina, A., Consoli, D., \& Gagliardi, D. (2005). A literature review on skills and innovation: How does successful innovation impact on the demand of skills and how do skills drive innovation? Manchester: ESRC Centre for Research on Innovation and Competition, University of Manchester.

Toner, P. (2011). Workforce skills and innovation: An overview of major themes in the literature. Paris: OECD.

Toner, P., Marceau, J., Hall, R., \& Considine, G. (2004). Innovation agents: Vocational education and training skills in the present and future Australian innovation system. In S. Dawe (Ed.), Vocational education and training and innovation: Research readings (pp. 84-105). Adelaide: NCVER.

Trow, M. (2006). Reflections on the transition from elite to mass to universal access: Forms and phases of higher education in modern societies since WWII. In J. J. F. Forest, \& P. G. Altbach (Eds.), International handbook of higher education (pp.243280). Dordrecht: Springer.

Van de Pol, J., Volman, M. \& Beishuizen, J. (2011). Patterns of contingent teaching in teacher-student interaction. Learning and Instruction, 21(1), 46-58.

Velde, C. (2009). Employers' perceptions of graduate competencies and future trends in higher vocational education in China. Journal of Vocational Education \& Training, 61(1), 35-51. 
Venter, K. (2003). Building on formal education: Employers' approaches to the training and development of new recruits in the People's Republic of China. International Journal of Training and Development, 7(3), 186-202.

Windschitl, M. (2002). Framing constructivism in practice as the negotiation of dilemmas: An analysis of the conceptual, pedagogical, cultural and political challenges facing teachers. Review of Educational Research, 72(2), 131-175.

Yin, R. (2003). Case study research design and method. Beverly Hills, CA: Sage.

\section{Appendix 1. Questionnaire Sample}

Table 4

Student Survey

\begin{tabular}{ll}
\hline Question & Answers \\
\hline $\begin{array}{l}\text { 1. Do you agree that modern education is undergone many changes? } \\
\text { 2. What do you think whether any new tendencies in vocational education } \\
\text { exist? }\end{array}$ & Yes, No, Not sure. \\
\hline $\begin{array}{l}\text { 3. Do you think whether the commitment to encourage the self-education as a } \\
\text { new tendency? }\end{array}$ & Yes, No, Not sure. \\
\hline $\begin{array}{l}\text { 4. Do you think whether new tendencies in vocational education are in } \\
\text { correlation with the development of information technologies? }\end{array}$ & Yes, No, Not sure \\
\hline $\begin{array}{l}\text { 5. Do you think that a remote education can be considered a new tendency? } \\
\text { 6. In your opinion, is it reasonable to refer the development of students' stress } \\
\text { resistance to new tendencies? }\end{array}$ & Yes, No, Not sure. \\
\hline $\begin{array}{l}\text { 7. Do you think that new tendencies in vocational education can contribute to } \\
\text { the latter? }\end{array}$ & Yes, No, Not sure. \\
\hline $\begin{array}{l}\text { 8. Do you agree that in your educational institution there are also new } \\
\text { tendencies? }\end{array}$ & Yes, No, Not sure. \\
\hline
\end{tabular}

